Article

\title{
Antimicrobial, Cytotoxic, Phytotoxic and Antioxidant Potential of Heliotropium strigosum Willd.
}

\author{
Muhammad Khurm ${ }^{1, *}$, Bashir A. Chaudhry ${ }^{1}$, Muhammad Uzair ${ }^{1}$ and Khalid H. Janbaz ${ }^{2}$ \\ 1 Faculty of Pharmacy, Natural Product Chemistry Unit, Bahauddin Zakariya University, Multan 60800, \\ Pakistan; drbashirahmadch@bzu.edu.pk (B.A.C.); muhammaduzair@bzu.edu.pk (M.U.) \\ 2 Akson College of Pharmacy, Mirpur University of Science and Technology, Mirpur 10250, Pakistan; \\ KHjanbaz@hotmail.com \\ * Correspondence: khuram.ghori19@gmail.com; Tel.: +92-305-604-9669
}

Academic Editor: James D. Adams

Received: 26 May 2016; Accepted: 21 July 2016; Published: 28 July 2016

\begin{abstract}
Background: Heliotropium strigosum Willd. (Chitiphal) is a medicinally important herb that belongs to the Boraginaceae family. Traditionally, this plant was used in the medication therapy of various ailments in different populations of the world. The aim of the study is to probe the therapeutic aspects of $H$. strigosum described in the traditional folklore history of medicines. Methods: In the present study, the dichloromethane crude extract of this plant was screened to explore the antimicrobial, cytotoxic, phytotoxic and antioxidant potential of H. strigosum. For antibacterial, antifungal and antioxidant activities, microplate alamar blue assay (MABA), agar tube dilution method and diphenyl picryl hydrazine (DPPH) radical-scavenging assay were used, respectively. The cytotoxic and phytotoxic potential were demonstrated by using brine shrimp lethality bioassay and Lemna minor assay. Results: The crude extract displayed positive cytotoxic activity in the brine shrimp lethality assay, with 23 of 30 shrimps dying at the concentration of $1000 \mu \mathrm{g} / \mathrm{mL}$. It also showed moderate phytotoxic potential with percent inhibition of $50 \%$ at the concentration of $1000 \mu \mathrm{g} / \mathrm{mL}$. The crude extract exhibited no significant antibacterial activity against Staphylococcus aureus, Shigella flexneri, Escherichia coli and Pseudomonas aeruginosa. Non-significant antifungal and radical scavenging activity was also shown by the dichloromethane crude extract. Conclusion: It is recommended that scientists focus on the identification and isolation of beneficial bioactive constituents with the help of advanced scientific methodologies that seems to be helpful in the synthesis of new therapeutic agents of desired interest.
\end{abstract}

Keywords: Heliotropium strigosum; antimicrobial activity; cytotoxicity; phytotoxicity; antioxidant activity; Boraginaceae family

\section{Introduction}

For the past few decades, the importance of medicinal plants for treating various infections has been tremendously increased because of the fact that a large number of people belonging to different populations depend upon the usage of phytomedicines due to the unavailability of primary healthcare facilities [1]. According to World Health Organization reports on phytomedicines, more than $25 \%$ of drugs which have been prescribed in recent years are obtained from different plant sources [2]. The family Boraginaceae is comprised of 100 genera and about 2000 species. The plants of this family are widely distributed in temperate, especially Mediterranean and tropical, regions. In Pakistan, this family is represented by 32 genera and 135 species. Moreover, some species, namely Cordia, Echium and Anchusa are cultivated [3]. Heliotropium, Cordia, Arnebia, Martensia and Trichodesma are the important genera of the Boraginaceae family. Fruits of Cordia are used as diaphoretic and sometimes as astringent [4]. The leaves and roots of Trichodesma indicum are effective against snake 
bites and urinary diseases and are used as a diuretic. The roots of this plant are also applied as a paste on swellings and joints and are used in dysentery in children [5]. Today, Alkanna (Alkanna tinctoria) root is used almost exclusively as a cosmetic dye. Orally, it has been used for diarrhea and gastric ulcers. Traditionally, Alkanna root has been used topically to treat skin wounds and diseases [6].

Heliotropium is one of the most complex and largest genera of the family Boraginaceae. In tropical and temperate regions, it was represented by 270-275 species while in Pakistan 23 species of this genus are present [3]. In folk medicinal history, species of genus Heliotropium have attained noticeable pharmacological importance. In Somalia, the pulp of roots of $H$. aegyptiacum was considered to be effective against scorpion stings and snake bites [7]. In India, the paste of the leaves of H. indicum was used for rheumatism [8]. In Mauritius, the decoction of whole plant of $H$. amplexicaule was used in the therapeutic management of coughs and fevers [9]. The variety of traditional medicinal uses of H. strigosum made it distinguishable among other species of genus Heliotropium. The powder and decoction of the whole plant material of $H$. strigosum has been used in the medication therapy of rheumatic arthritis and jaundice and it is also used as a blood purifier [10]. The paste of roots of this plant is used for healing wounds [11]. For the curing of snake bites, gum boils, eye sores and nettle stings, the juice of this whole plant is administered [12]. This juice has also been used as diuretic and demonstrated some laxative effect [13]. In the current study, the dichloromethane crude extract of H. strigosum was examined for different biological activities, which could be related to the potential therapeutic value of this plant as prescribed in traditional medicine.

\section{Experimental Section}

\subsection{Materials and Methods}

The current study was conducted in the natural product chemistry laboratory, Faculty of Pharmacy, Bahauddin Zakariya University, new campus Multan and International Centre for Chemical and Biological Sciences, Hussain Ebrahim Jamal Research Institute of Chemistry, University of Karachi, Karachi, Pakistan, from August 2014 to August 2015.

\subsection{Collection and Identification of Plant Material}

The plant Heliotropium strigosum was collected in September 2014 from the surroundings of the railway ground district Khanewal (Pakistan) and identified by Dr. Muhammad Zafarullah, Assistant professor of Institute of Pure and Applied Biology, Bahauddin Zakariya University, Multan, Pakistan. A voucher no. "Stewart 591" was assigned to the specimen and preserved in the University herbarium.

\subsection{Preparation of Dichloromethane Extract}

Drying of the whole plant material was achieved by placing it under shade on old newspapers for 25 days to accomplish the process of effective extraction. When the plant material was completely dried, it was made into a coarse powder by crushing in the grinding mill. The extraction of this powdered plant material was carried out by the process of simple maceration. About $600 \mathrm{~g}$ of measured powdered material was put into the extraction bottle and a known volume of dichloromethane $(3 \times 1.5 \mathrm{~L})$ was added into the bottle. For the purpose of maximum possible extraction, the mixture was continuously shaken after every $15 \mathrm{~min}$ for 3 to $4 \mathrm{~h}$ and then make it homogenized by the method of ultra-sonication. After $24 \mathrm{~h}$, this mixture was filtered off. Repeated the same procedure thrice with dichloromethane. After the third collection, the dichloromethane extract was concentrated separately with the help of a rotary evaporator. This was done under reduced pressure. Then the dichloromethane extract was collected in the separated sample bottle and assigned the code as HSWPD (Heliotropium strigosum whole plant dichloromethane extract). The powdered plant material yielded $5.15 \mathrm{~g}$ of crude dichloromethane extract which is approximately $0.85 \%$ of total dry weight. 


\subsection{Antimicrobial Assays}

\subsubsection{Antibacterial Assay-Microplate Alamar Blue Assay (MABA)}

The dichloromethane extract of H. strigosum was tested for significant antibacterial activity by using microplate alamar blue assay (MABA) (Invitrogen Corporation, San Diego, CA, USA). Strains of four pathogenic bacteria such as Staphylococcus aureus (NCTC 6571), Shigella flexneri, Pseudomonas aeruginosa (ATCC 10145) and Escherichia coli (NCTC 10418) were used in this assay. Mueller Hinton medium was prepared in a separate petri dish by following the specifications and guidelines given by the manufacturer (Sigma-Aldrich, St. Louis, MO, USA) and adjusted the pH to 6.6-7.3 normally at $25^{\circ} \mathrm{C}$. In this method, the tested micro-organisms were cultured in Mueller Hinton medium. Then the adjustment of turbidity index of inoculums up to $0.5 \mathrm{McF}$ arland was done. We prepared the standard solution of $1 \mathrm{~g}$ dichloromethane crude extract in $1 \mathrm{~mL}$ sterile dimethyl sulfoxide (DMSO) and distributed the above prepared media into the wells. This work was repeated thrice. All the tested micro-organisms were also placed into the wells. We made sure that the control wells did not contain any testing organism. The volume of well plate 96 was settled up to the level of $200 \mu \mathrm{L}$. At the end, added $5 \times 10^{6}$ cells into all the control and testing wells. Sealed all the plates with the help of paraffin. We placed these plates into the incubator at $37^{\circ} \mathrm{C}$ for at least $18-20 \mathrm{~h}$ without shaking. After $20 \mathrm{~h}$, we added $5 \mu \mathrm{L}$ alamar blue dye into every well and shook gently at the speed of 80 revolutions per minute for $2-3 \mathrm{~h}$ by using the shaking incubator at $37^{\circ} \mathrm{C}$. Plates were covered with foil in shaking incubator. If the color of alamar blue dye was changed from blue to pink, it confirmed the growth of bacteria. Finally, the absorbance at the wavelength of $570 \mathrm{~nm}-600 \mathrm{~nm}$ was recorded with the help of Elisa reader [14].

\subsubsection{Antifungal Assay-Agar Tube Dilution Method}

The dichloromethane extract of whole plant of $H$. strigosum was tested for certain antifungal activity against six fungal strains such as Trychophyton rubrum, Aspergillus niger, Fusarium solani, Candida albicans and Microsporum canis by using agar tube dilution assay. We took $24 \mathrm{mg}$ of dichloromethane crude extract and mixed in $1 \mathrm{~mL}$ sterile dimethyl sulfoxide (DMSO) to prepare its stock solution. For the preparation of Sabouraud dextrose agar (SDA) medium, we dissolved $32.5 \mathrm{~g}$ of Sabouraud glucose $(2 \%)$ or maltose agar in $500 \mathrm{~mL}$ of distilled water. Adjusted the $\mathrm{pH}$ of this medium up to 5.5-5.6. Steaming of this media was done to dissolve all the suitable contents and added an appropriate volume $(4 \mathrm{~mL})$ into the test tubes having screw caps. These tubes were placed into the autoclave for $15 \mathrm{~min}$ at the temperature of $121^{\circ} \mathrm{C}$. After this, these tubes were placed at the temperature of $50{ }^{\circ} \mathrm{C}$ to achieve the effective cooling. Then, we loaded the non-solidified agar media by using pipette with $66.6 \mu \mathrm{L}$ of tested sample taken from the stock solution. At room temperature, these tubes were placed for solidification in a slanting position. In every tube, a piece of fungus obtained from the seven day old fungus culture with the diameter of $4 \mathrm{~mm}$ was inoculated. All these tubes containing culture of fungus were placed in the incubator at the optimum temperature of $27^{\circ} \mathrm{C}-29^{\circ} \mathrm{C}$. These culture containing tubes were allowed to grow for 3-7 days. This culture was observed twice a week during the period of incubation. When the incubation for 3-7 days was completed, the tube in which the growth of fungus culture was not visible was taken for the measurement of MIC value of the tested sample which is expressed in $\mu \mathrm{g} / \mathrm{mL}$ [15].

\subsection{Cytotoxic Assay_Brine Shrimp Lethality Bioassay}

We stored the brine shrimp (Artemia salina Leach) eggs usually at the very low temperature of $4^{\circ} \mathrm{C}$. When filtration of brine solution was achieved, the hatching tray was filled half with this solution. Then we sprinkled eggs $(50 \mathrm{mg})$ on the hatching try and incubated at the temperature of $37^{\circ} \mathrm{C}$. Then, we prepared the stock solution by taking $20 \mathrm{mg}$ of crude dichloromethane extract and dissolved it in $2 \mathrm{~mL}$ of sterile dimethyl sulfoxide. From this stock solution, we transferred $5 \mu \mathrm{L}, 50 \mu \mathrm{L}$ and $500 \mu \mathrm{L}$ into three separate glass vials at the concentrations of $(10,100$ and 1000$) \mu \mathrm{g} / \mathrm{mL}$ by using micro-pipette. 
We placed these solvent containing vials over night for the evaporation of solvent. After two days of hatching process, we placed 10 larvae individually in the vials by using Pasteur pipette. We made the final volume of solvent up to $5 \mathrm{~mL}$ with the addition of sea water. These vials were placed into the incubator at the temperature of $25-27^{\circ} \mathrm{C}$ for $24 \mathrm{~h}$ beneath the illumination. We took an extra two vials, one of which had the standard cytotoxic drug (Etoposide) served as positive control and the other vials in which respective solvent was added and served as negative control. Larvae were observed in each vial after $24 \mathrm{~h}$. The number of survivors should be determined. Finney computerized system (Probit analysis) was used to analyze the data for the determination of $\mathrm{LD}_{50}$ values with $95 \%$ confidence intervals. Shrimps can be used $48-72 \mathrm{~h}$ after the initiation of hatching. After $72 \mathrm{~h}$ they should be discarded [15-17].

\subsection{Phytotoxic Assay_Lemna Bioassay for Phytotoxicity}

We prepared the inorganic E-medium (stock solution) by mixing appropriate inorganic constituents [15] into 1 liter of distilled water. The $\mathrm{pH}$ of E-medium was adjusted by adding potassium hydroxide pellets up to 6-7. To prepare the working E-medium, $100 \mathrm{~mL}$ of this stock solution was taken and dissolved it in $900 \mathrm{~mL}$ of distilled water. Then, we prepared the solution of tested crude extract by dissolving $30 \mathrm{mg}$ of crude extract in $1.5 \mathrm{~mL}$ of ethyl alcohol. Three flasks were taken and pipetted $10 \mu \mathrm{L}, 100 \mu \mathrm{L}$ and $1000 \mu \mathrm{L}$ into these flasks from concentration solutions of $(10,100$ and 1000$) \mu \mathrm{g} / \mathrm{mL}$. Placed these solvent containing flasks over night for the evaporation of solvent. In each flask, added $20 \mathrm{~mL}$ stock solution of working E-medium along with the addition of 2 to 3 fronds (total fronds used 20) from the rosette of the plant Lemna minor. Two supplemented flasks, one with the standard drug (Paraquat) and other with the E-medium were served as positive and negative control respectively. We placed all these flasks into the growth chamber for 7 days by maintaining the temperature at $28^{\circ} \mathrm{C}$ along with the light intensity of 9000 lux and relative humidity of $56 \% \pm 10 \%$. When the incubation period was completed, counted and verified the number of fronds of each flask on the 7th day $[18,19]$. The results which were analyzed as growth inhibition (\%), compared with reference drug to negative control were given as shown below.

$\%$ inhibition of growth $=100-($ No. of fronds in tested sample/No. of fronds in negative control $) \times 100$

\subsection{Antioxidant Assay-DPPH (2,2-Diphenyl-1-Picrylhydrazl) Radical Scavenging Assay}

We dissolved the weighed amount of tested sample in a suitable volume of pure dimethyl sulfoxide. Then we prepared the $300 \mu \mathrm{L}$ solution of DPPH (2,2-diphenyl-1-picrylhydrazl) by using appropriate volume of pure ethyl alcohol. About $5 \mu \mathrm{L}$ of the tested sample solution was added into the 96-well plate and measured the absorbance at the wavelength of $515 \mathrm{~nm}$. After this, to each well was added $95 \mu \mathrm{L}$ solution of DPPH. We then incubated the 96 well plate at the temperature of $37^{\circ} \mathrm{C}$ for the period of $30 \mathrm{~min}$. We covered this plate with paraffin so that the solvent evaporation must be avoided. The pure dimethyl sulfoxide was served as control. By using a micro-plate reader, final absorbance at the wavelength of $515 \mathrm{~nm}$ was recorded. Percentage of radical scavenging activity (\%RSA) can be determined by the following equation [20].

$\%$ RSA $=100-($ Original dose of tested sample/Original dose of control $) \times 100$

\section{Results}

\subsection{Antibacterial Activity}

In the present study, antibacterial potential of crude dichloromethane extract was examined. The percent (\%) inhibition showed by sample extract against various tested bacteria are specified in the Table 1 . The results of preliminary antibacterial activity demonstrated that the dichloromethane crude extract of $H$. strigosum showed inhibition up to $16 \%$ against $S$. aureus while against $S$. flexneri, 
and showed an inhibition of 3\% respectively at the concentration used, which is $150 \mu \mathrm{g} / \mathrm{mL}$. The pathogens E. coli and P. aeruginosa showed no inhibition against the tested sample. Thus, crude dichloromethane extract showed non-significant antibacterial activity against all the four tested bacterial strains when compared with the reference drug used, which was Ofloxacin $(0.25 \mu \mathrm{g} / \mathrm{mL})$.

Table 1. Results of preliminary antibacterial assay of H. strigosum.

\begin{tabular}{ccc}
\hline Name of Bacteria & Percent (\%) Inhibition of Tested Sample & Percent (\%) Inhibition of Standard Drug (Ofloxacin) \\
\hline S. aureus & 16 & 92.35 \\
E. coli & 0 & 90.20 \\
P. aeruginosa & 0 & 89.35 \\
S. flexneri & 3 & 91.40 \\
\hline
\end{tabular}

Concentration of tested sample used $=150 \mu \mathrm{g} / \mathrm{mL}$; Concentration of standard drug used $=0.25 \mu \mathrm{g} / \mathrm{mL}$; Positive control = Ofloxacin (standard antibiotic); Negative control = DMSO (Dimethyl sulfoxide); Percent inhibition activity, 0-39 = Low (non-significant); 40-59 = moderate; 60-69 = Good; above 70 = Significant.

\subsection{Antifungal Activity}

The dichloromethane extract of the whole plant of H. strigosum was tested for significant antifungal activity. The results shown by tested crude extract against different fungal strains are given in Table 2 . The results revealed that none of the tested fungal strains showed any kind of inhibition against the tested sample. So, the dichloromethane extract was found to be inactive against all the tested fungus species at the concentration of the sample used $(400 \mu \mathrm{g} / \mathrm{mL})$.

Table 2. Results of antifungal assay of H. strigosum.

\begin{tabular}{|c|c|c|c|c|c|}
\hline \multirow{2}{*}{ Name of Fungus } & \multicolumn{2}{|c|}{ Linear Growth (mm) } & \multirow{2}{*}{ \% Inhibition (Tested Sample) } & \multirow{2}{*}{ Standard Drug } & \multirow{2}{*}{$\operatorname{MIC}(\mu \mathrm{g} / \mathrm{mL})$} \\
\hline & Sample & Control & & & \\
\hline T. rubrum & 100 & 100 & 0 & Miconazole & 97.8 \\
\hline A. niger & 100 & 100 & 0 & Amphotericin B & 20.70 \\
\hline F. solani & 100 & 100 & 0 & Miconazole & 73.50 \\
\hline C. albicans & 100 & 100 & 0 & Miconazole & 113.1 \\
\hline M. canis & 100 & 100 & 0 & Miconazole & 98.1 \\
\hline
\end{tabular}

MIC $=$ Minimum inhibitory concentration; Concentration of tested sample used $=400 \mu \mathrm{g} / \mathrm{mL}$; Percent inhibition activity, $0-39=$ Low (non-significant); 40-59 = moderate; 60-69 = Good; above 70 = Significant; Positive control = Miconazole and Amphotericin B (A. niger); Negative control = DMSO (Dimethyl sulfoxide).

\subsection{Cytotoxic Activity}

Brine shrimp lethality bioassay was used for cytotoxic screening of dichloromethane extract of the whole plant of H. strigosum. The consequences of dichloromethane screening are expressed in Table 3. The results showed that, at the concentration of $10 \mu \mathrm{g} / \mathrm{mL}$ and $100 \mu \mathrm{g} / \mathrm{mL}$, the number of dead shrimps was only one. However, when the concentration of the tested sample increased up to $1000 \mu \mathrm{g} / \mathrm{mL}$, the number of dead shrimps was 23 and only 7 shrimps survived. Thus, from the above revealed data, an $\mathrm{LD}_{50}$ of $462 \mu \mathrm{g} / \mathrm{mL}$ was calculated as compared with the reference agent (etoposide) that resulted in an $\mathrm{LD}_{50}$ of $7.46 \mu \mathrm{g} / \mathrm{mL}$.

Table 3. Results of brine shrimp lethality bioassay of $H$. strigosum.

\begin{tabular}{|c|c|c|c|c|c|}
\hline Dose of Tested Sample $(\mu \mathrm{g} / \mathrm{mL})$ & No. of Shrimps & No. of Survivors & $\mathrm{LD}_{50}(\mu \mathrm{g} / \mathrm{mL})$ & Standard Drug & $\mathrm{LD}_{50}(\mu \mathrm{g} / \mathrm{mL})$ \\
\hline 100 & 30 & 29 & 462 & Etoposide & 7.46 \\
\hline
\end{tabular}

Positive control = Etoposide; Negative control = DMSO (Dimethyl sulfoxide); No. of replicates = 3; Incubation conditions $=28 \pm 1{ }^{\circ} \mathrm{C}$. 


\subsection{Phytotoxic Activity}

The phytotoxic potential of dichloromethane extract of whole plant of H. strigosum was studied by using Lemna minor phytotoxicity bioassay. The growth inhibition (\%) shown by the tested crude extract is given in Table 4. The results revealed that the tested sample showed percent growth inhibition up to $35 \%$ and $40 \%$ at the concentration of 10 and $100 \mu \mathrm{g} / \mathrm{mL}$ but at the concentration of $1000 \mu \mathrm{g} / \mathrm{mL}$, it showed $50 \%$ growth inhibition. So, the dichloromethane extract exhibited low phytotoxic activity at the concentrations of 10 and $100 \mu \mathrm{g} / \mathrm{mL}$ but showed moderate activity at the highest tested concentration that was $1000 \mu \mathrm{g} / \mathrm{mL}$ when compared with the standard drug (Paraquat) which inhibited the growth of L. minor at the concentration of $0.015 \mu \mathrm{g} / \mathrm{mL}$.

Table 4. Results of phytotoxicity assay of H. strigosum.

\begin{tabular}{|c|c|c|c|c|c|}
\hline \multirow{2}{*}{ Name of Plant } & \multirow{2}{*}{$\begin{array}{l}\text { Concentration of Tested } \\
\text { Sample }(\mu \mathrm{g} / \mathrm{mL})\end{array}$} & \multicolumn{2}{|c|}{ No. of Fronds } & \multirow{2}{*}{$\begin{array}{l}\text { \% Growth } \\
\text { Inhibition }\end{array}$} & \multirow{2}{*}{$\begin{array}{c}\text { Concentration of Standard } \\
\text { Drug (Paraquat) }(\mu \mathrm{g} / \mathrm{mL})\end{array}$} \\
\hline & & Sample & Control & & \\
\hline \multirow{3}{*}{ Lemna minor } & 10 & 13 & \multirow{3}{*}{20} & 35 & \multirow{3}{*}{0.015} \\
\hline & 100 & 12 & & 40 & \\
\hline & 1000 & 10 & & 50 & \\
\hline
\end{tabular}

Positive control $=$ Paraquat; Negative control $=$ Volatile solvent (ethanol); Incubation conditions $=28 \pm 1{ }^{\circ} \mathrm{C}$.

\subsection{Antioxidant Activity}

DPPH radical scavenging assay was used to determine the significant antioxidant activity of dichloromethane extract of the whole plant of $H$. strigosum. The radical scavenging activity exhibited by the tested dichloromethane extract is shown in Table 5 . The results demonstrated that the crude extract showed non-significant antioxidant potential with very low radical scavenging activity up to $13 \%$ at the tested concentration that was $500 \mu \mathrm{M}$ when compared with $\mathrm{N}$-acetyl cysteine (standard drug) which exhibited significant radical scavenging activity up to $96 \%$ with $\mathrm{IC}_{50}$ of $111.44 \pm 0.7 \mu \mathrm{M}$ respectively at the same concentration.

Table 5. Results of diphenyl picryl hydrazine (DPPH) radical scavenging assay of H. strigosum.

\begin{tabular}{ccc}
\hline Concentration of Tested Sample $(\mu \mathbf{M})$ & \% RSA (Radical Scavenging Activity) & IC $_{\mathbf{5 0} \pm \mathbf{S E M}(\mu \mathbf{M})}$ \\
\hline $500^{\mathrm{a}}$ & 13 & $>500$ \\
$500^{\mathrm{b}}$ & 96 & $111.44 \pm 0.7$ \\
\hline
\end{tabular}

${ }^{\mathrm{a}}=$ Dichloromethane extract; $^{\mathrm{b}}=\mathrm{N}$-acetyl cysteine (Standard drug \& Positive control); Negative control = DMSO (Dimethyl sulfoxide); $\mu \mathrm{M}=$ Micro-molar $\left(10^{-3} \mathrm{~mol} / \mathrm{m}^{3}\right) ; \mathrm{SEM}=$ Standard error mean; Data is expressed as mean \pm SEM of three independent readings.

\section{Discussion}

The history of human beings has revealed that, for the past 60,000 years, plants have been used as a source of treating various ailments in different civilizations of the world [21]. Due to the increased resistance of microbes worldwide, scientists are always looking for the development of newer antibacterial agents [22]. Medicinal plants are considered as a source in the discovery and advancement of new pharmaceuticals which are effective in the management of different diseases $[23,24]$. In our study, the dichloromethane extract of whole plant material of H. strigosum showed non-significant antibacterial activity against S. aureus, S. flexneri, E. coli and P. aeruginosa. The results of our studies are quite comparable with the antibacterial activity revealed by other species of genus Heliotropium and some other plant species of different families. The petroleum ether and chloroform fractions of ethanolic extract of $H$. subulatum showed strong antibacterial activity against E. coli, S. aureus, Streptococcus pneumonia and Bacillus subtilis. That strong antibacterial activity might be due to the purification of five pyrrolizidine alkaloids from this plant [25]. The methaolic extract of aerial parts of $H$. indicum has broad spectrum antibacterial activity against S. aureus, 
S. pneumonia, Salmonella typhi, E. coli and Klebsiella pneumonia [26]. The antibacterial significance of plant extracts is attributed mainly to the presence of terpenoids [27]. The sterols and triterpenoids such as $\beta$-sitosterol, stigmasterol, $\beta$-amyrin, friedelan- $\beta$-ol, cycloartenone, $\beta$-amyrin acetate and friedelin isolated from ethanol extract of the whole plant of $H$. ellipticum exhibited strong antibacterial activity against E. coli, S. aureus and K. pneumonia [28]. Filifolinol, one of the geranyl aromatic derivatives isolated from $H$. sclerocarpum and $H$. filifolium also showed significant antibacterial activity against S. aureus, Bacillus cereus, B. subtilis and Micrococcus luteus $[29,30]$. Another reported antibacterial potential was shown by the group of new $3 H$-Spiro[1-benzofuran-2,1'-cyclohexane] derivatives such as $3^{\prime}$-hydroxy-2', $2^{\prime}, 6^{\prime}$-trimethyl-3H-spiro[1-benzofuran-2, $1^{\prime}$-cyclohexane]-5-carboxylic acid, methyl $3^{\prime}$-acetyloxy-2' $, 2^{\prime}, 6^{\prime}$-trimethyl-3H-spiro[1-benzofuran-2, $1^{\prime}$-cyclohexane]-5-carboxylate, methyl $3^{\prime}$-isopentanoyloxy-2', $2^{\prime}, 6^{\prime}$-trimethyl-3H-spiro[1-benzofuran-2, $1^{\prime}$-cyclohexane]-5-carboxylate, and methyl $3^{\prime}$-benzoyloxy-2' $2^{\prime} 2^{\prime}, 6^{\prime}$-trimethyl-3H-spiro[1-benzofuran-2, $1^{\prime}$-cyclohexane]-5-carboxylate isolated from the dichloromethane cuticle extract of $H$. filifolium against several gram positive and gram negative bacteria [31]. In addition to the genus Heliotropium, other plant species also exhibited antibacterial potential. The ethanolic extracts of Curcuma longa and Alpinia galangal displayed weak antibacterial activity against $S$. aureus and S. typhi and showed no inhibition against B. subtilis, E. coli, P. aeruginosa and S. flexneri [32]. Thus, from the above contributions, researchers have come to know that the identification, isolation and purification of different groups of organic compounds, mainly pyrrolizidine alkaloids, terpenoids and flavonoids, from H. strigosum should reveal that this plant has a perceptible future role in the field of antibacterial medicinal agents.

Different pathogenic fungi cause systemic infections of the skin, lungs, liver, mouth and blood [33-35]. Fungal attacks especially infect the skin and cause severe infections such as athlete's foot, tinea cruris and numerous others [36]. Only 10 antifungal drugs are permitted for the therapeutic management of invasive systemic fungal infections by the Food and Drug Administration (FDA) authority in United States of America [37]. Patients who have had pediatric lung transplantation are at serious risk of pulmonary fungal infection [33]. In the present study, the dichloromethane extract of whole plant material of $H$. strigosum demonstrated no antifungal activity and was found to be inactive against all the tested fungal strains. These results exposed the antifungal principles in a consistent manner, as established by different plant species of the family Boraginaceae and some other families. The methanolic extract of Echium rauwolfii and E. horridum showed no antifungal activity against Aspergillus flavus but were found to have weak activity against C. albicans [38]. The dichloromethane extract of Cordia curassavica [39] and Cordia linnael [40] showed equal antifungal activity to some extent against both $C$. albicans and Clasdosporium cucumerinum. The benzene extract of Trichodesma amplexicaule remained inactive against Aspergillus niger and A. flavus followed by chloroform extract with very low activity against these micro-organisms [41]. The ethyl acetate and n-butanol fractions of methanolic extract of Onosma griffithii reported no antifungal activity [42]. The ethyl alcohol and aqueous extracts of Colendia procumbens never showed antifungal activity against C. albicans [43]. No antifungal activity was displayed by the methanolic and aqueous extracts of Trichodesma zeylanicum and Anchusa italic [44]. Apart from the above consequences, different biological extracts and isolated bioactive constituents, mainly pyrrolizidine alkaloids and terpenoids from different Heliotropium species such as H. indicum [45], H. ellipticum [28,46] and H. marifolium [47], demonstrated significant antifungal activity against various pathogenic fungi. Our study reports for the first time the dichloromethane screening of $H$. strigosum for antifungal potential.

Due to the life threatening effects of cancer, it is known as a critical factors that increases the mortality rate worldwide. Cancer of the liver, lung, colon and stomach contribute to a major proportion of mortality cases all over the world [48]. In the present research work, the dichloromethane extract of H. strigosum shows positive cytotoxic activity with an $\mathrm{LD}_{50}$ of $462 \mu \mathrm{g} / \mathrm{mL}$. The cytotoxic potential of this plant is extremely compatible with the previously reported developments in the field of antitumor drug discovery. The ethanolic, dichloromethane and n-hexane extracts of H. subulatum [49] and the methanolic extract of $H$. indicum [50] showed significant antineoplastic activity in the dose dependent 
manner. The ethanolic extracts of Curcuma longa and Alpinia galangal revealed strong cytotoxic potential with the $\mathrm{LD}_{50}$ of $33 \mu \mathrm{g} / \mathrm{mL}$ and $109 \mu \mathrm{g} / \mathrm{mL}$, respectively [32]. The occurrence of cytotoxic activity was mainly due to the presence of different classes of organic compounds such as phenolic compounds (polyphenols), catechins and flavonoid constituents. A large number of polyphenols and flavonoids have been purified and isolated from different parts of Bruguiera gymnorrhiza, Blumea lacera, Aegiceras corniculatum, Hygrophila auriculata and Hibiscus tiliaceous, which might be responsible for their cytotoxic activity. In 2007, a scientific report from Bangladesh examined 32 extracts of 16 different Bangladehsi plant species for their cytotoxic potential. Among these tested extracts, the aqueous extracts possessed very low cytotoxic potential. This low antitumor potential of aqueous extracts is of great therapeutic significance because traditionally they are used in the medication of various ailments instead of cancer [51]. Another informative description of cytotoxic potential was reported in Brazil in which 60 species of different medicinal plants were screened to examine the cytotoxic activity. Only $10 \%$ of plant species showed better cytotoxicity with $\mathrm{ED}_{50}$ less than 1000 ppm [16]. In most of the reported statistical data about the cytotoxic potential of different medicinal plants, scientists used brine shrimp lethality bioassay instead of other scientific approaches because a progressive correlation existed between the toxicity of brine shrimp and human nasopharyngeal carcinoma [52].

In the developing countries, weeds are considered an important factor for environmental protection. Approximately 30,000 different species of weeds are present in the world, out of which a reported 1800 cause the loss of $9.7 \%$ of crop yields [53]. The presence of weeds reduced the agricultural productivity of crops that lead to massive economical loss among different regions of the world. In a recent study, the dichloromethane extract of $H$. strigosum demonstrated moderate phytotoxic activity at the higher tested concentration $(1000 \mu \mathrm{g} / \mathrm{mL})$ but showed low phytotoxic activity at the concentration of 10 and $100 \mu \mathrm{g} / \mathrm{mL}$ with the growth inhibition of $35 \%$ and $40 \%$. The phytotoxic significances of this plant are followed by some other species of genus Heliotropium such as H. dasycarpum whose methanol and dichloromethane extract showed 100\% inhibitory effect at the concentration of $1000 \mu \mathrm{g} / \mathrm{mL}$, respectively [54]. Similar phytotoxic measurements were shown by ethanolic extract of Curcuma longa and Alpinia galangal [32]. The methanolic extract of polygonatum verticillatum exhibited significant phytotoxic activity at the tested doses of 5,50 and $500 \mu \mathrm{g} / \mathrm{mL}$ [55]. A few scientific descriptions of allelopathic approaches of $H$. indicum [56] and Chrysanthemum morifolium [57] were also considered. The reduction of crops quantity and quality is given serious attention by the scientists who focus upon the discovery and development of newer weedicides because chemically synthetic weedicides cause harmful adverse effects, mainly the expansion of weedicide resistant populations, lowering the water and soil consumption and resulting in damaging effects on non-targeted organisms [53].

The destructive effects of free radicals can be prevented by using different organic and inorganic substances having low molecular weight. Some of the commonly used antioxidative agents are tocopherols, copper, vitamin C, zinc, thiols, iron and manganese [58]. The recent scientific studies also exposed the beneficial preventive effects of antioxidants in the treatment of cardiovascular diseases, ocular damage and certain type of cancers [59]. The consequences of our study shows that the dichloromethane extract of $H$. strigosum demonstrated very low radical scavenging activity, only up to $13 \%$. Therefore, no antioxidant activity was shown by the tested extract and it was found to be inactive. However, some other species of genus Heliotropium showed excellent radical scavenging activity because of the presence of flavonoids. Flavonoids are the largest group of naturally occurring phenolic compounds and possessed some chemical and biological properties which are very helpful in the prevention of free radicals formation. Flavonoids are found to be ubiquitous in most of the plants growing in extreme conditions [60]. A new compound belonging to the group of flavanones named as Naringenin was identified and isolated from the resinous exudate of dichloromethane extract of H. sclerocarpum which displayed outstanding free radical scavenging activity [30]. In 2009, from the resinous exudates of dichloromethane extract of $H$. taltalense, three flavonoids, namely Naringenin, 3-O-methylgalangin and 7-O-methyleriodictiol were isolated and exhibited significant antioxidant activity [61]. The isolation of three new flavonoids, namely, 5,3'-dihydroxy-7,4' -dimethoxyflavanone, 
5,4'-dihydroxy-7-methoxyflavanone and 4'-acetyl-5-hydroxy-7-methoxyflavanone from H. glutinosum was also reported [60]. From $H$. sinuatum, eight previously reported flavonoids along with one new compound 4-(3',5'-dihydroxynonadecyl) phenol were isolated, which confirmed the antioxidant behavior of this plant [62]. All the above previous scientific reports confirmed that all these plants showed exceptional antioxidant potential. This gives scientists a new approach to identify, purify and isolate the flavonoids and other phenolic compounds from $\mathrm{H}$. strigosum which lead towards the synthesis of new antioxidant agents in the world of medicines.

\section{Conclusions}

The dichloromethane screening of Heliotropium strigosum was done for the first time. The crude extract of this plant showed low antibacterial activity against two bacterial stains, one is gram positive and other is gram negative. There was no antifungal activity shown by the tested crude extract. The dichloromethane extract exhibited positive cytotoxic and moderate phytotoxic potential at the highest tested concentrations. No antioxidant behavior was exposed by this plant. In conclusion, scientists and pharmacologists should pay serious attention to the screening of this plant by using some other scientific bioassay methodologies which might serve as a source for the identification, purification and isolation of beneficial bioactive constituents that seems to be helpful in the synthesis of new therapeutic agents of desired interest. Therefore, in the future, Heliotropium strigosum will be used globally as a source of safer phytomedicines.

Acknowledgments: We shall be very thankful to the management of Faculty of Pharmacy, Bahauddin Zakariya University, Multan and International Center for Chemical and Biological Sciences, Hussain Ebrahim Jamal Research Institute of Chemistry for providing us the necessary resources to perform these studies.

Author Contributions: Bashir Ahmed Chaudhry and Muhammad Uzair conceived and designed the project. Muhammad Khurm collected the plant material, performed the experiments and wrote the manuscript. Khalid Hussain Janbaz analyze the results and made the necessary corrections.

Conflicts of Interest: The authors declare no conflict of interest.

\section{References}

1. Shanmugam, S.; Bhavani, P. Studies on the comparison of phytochemical constituents and antimicrobial activity of Curcuma longa varieties. Int. J. Curr. Microbiol. Appl. Sci. 2014, 3, 573-581.

2. $\quad$ Pranuthi, E.K.; Narendra, K.; Swathi, J.; Sowjanya, K.; Reddi, K.R.; Emmanuel, R.F.S.; Satya, A.K. Qualitative Assessment of Bioactive Compounds from a Very Rare Medicinal Plant Ficus dalhousiae Miq. J. Pharmacogn. Phytochem. 2014, 3, 57-61.

3. Nasir, E.; Ali, S. Flora of West Pakistan, 4th ed.; Feroz Sons Press: Karachi, Pakistan, 1974; p. 23.

4. Ghori, M.K.; Ghaffarı, M.A.; Hussain, S.N.; Manzoor, M.; Azız, M.; Sarwer, W. Ethnopharmacological, phytochemical and pharmacognostic potential of genus Heliotropıum L. Turk. J. Pharm. Sci. 2016, 13, $143-168$. [CrossRef]

5. Shinwari, M.I.; Khan, M.A. Folk use of medicinal herbs of Margalla hills national park, Islamabad. J. Ethnopharmacol. 2000, 69, 45-56. [CrossRef]

6. Bisset, N.G. Max Wichtl's Herbal Drugs \& Phytopharmaceuticals; CRC Press: Boca Raton, FL, USA, 1994.

7. Thulin, M. Flora of Somalia; CRB Press: Harare, NY, USA, 1993; Volume 1.

8. Nagaraju, N.; Rao, K. A survey of plant crude drugs of Rayalaseema, Andhra Pradesh, India. J. Ethnopharmacol. 1990, 29, 137-158. [CrossRef]

9. Schmelzer, G.; Gurib-Fakim, A. Plant Resources of Tropical Africa; Backurys Publishers: Leiden, The Netherlands, 2008; Volume 11.

10. Ahmad, S.; Alam, K.; Wariss, H.; Anjum, S.; Mukhtar, M. Ethnobotanical studies of plant resources of Cholistan desert, Pakistan. Int. J. Sci. Res. 2014, 3, 1782-1788.

11. Watanabe, T.; Rajbhandari, K.R.; Malla, K.J.; Yahara, S. A Hand Book of Medicinal Plants of Nepal; Kobfai Publishing Project: Bangkok, Thailand, 2005; Volume 15.

12. Roeder, E.; Wiedenfeld, H. Pyrrolizidine alkaloids in medicinal plants of Mongolia, Nepal and Tibet. Die Pharm. Int. J. Pharm. Sci. 2009, 64, 699-716. 
13. Mahmood, A.; Mahmood, A.; Shaheen, H.; Qureshi, R.A.; Sangi, Y.; Gilani, S.A. Ethno medicinal survey of plants from district Bhimber Azad Jammu and Kashmir, Pakistan. J. Med. Plants Res. 2011, 5, 2348-2360.

14. Pettit, R.K.; Weber, C.A.; Kean, M.J.; Hoffmann, H.; Pettit, G.R.; Tan, R.; Horton, M.L. Microplate Alamar blue assay for Staphylococcus epidermidis biofilm susceptibility testing. Antimicrob. Agents Chemother. 2005, 49, 2612-2617. [CrossRef] [PubMed]

15. Atta-ur-Rahman; Choudhary, M.I.; William, J.T. Bioassay Techniques for Drug Development; CRC Press: Reading, UK, 2001; pp. 8-23.

16. Alves, T.M.D.A.; Silva, A.F.; Brandao, M.; Grandi, T.S.M.; Smania, E.D.F.A.; Smania, J. Biological screening of Brazilian medicinal plants. Mem. Inst. Oswaldo Cruz 2000, 95, 367-373. [CrossRef] [PubMed]

17. Mayer, B.N.; Ferrigni, N.R.; Putnam, J.E.; Jacobsen, L.B.; Nicholas, P.E.; McLaughin, J.L. Brine Shrimp: A convenient general bioassay for active plant constituents. Planta Med. 1982, 45, 31-34. [CrossRef] [PubMed]

18. Atta-ur-Rehman. Studies in Natural Product Chemistry; Elsevier Science Publishers: Amsterdam, The Netherlands, 1991; Volume 9, pp. 383-409.

19. Rashid, R.; Farah, M.; Mirza, M.N. Biological screening of Salvia cabulica. Pak. J. Bot. 2009, 41, 1453-1462.

20. Uddin, N.; Siddiqui, B.S.; Begum, S.; Bhatti, H.A.; Khan, A.; Parveen, S.; Choudhary, M.I. Bioactive flavonoids from the leaves of Lawsonia alba (Henna). Phytochem. Lett. 2011, 4, 454-458. [CrossRef]

21. Sumner, J. The Natural History of Medicinal Plants; Timber Press: Portland, OR, USA, 2000; Volume 1.

22. Ullah, F.; Malik, S.; Ahmed, J. Antibiotic susceptibility pattern and ESBL prevalence in nosocomial Escherichia coli from urinary tract infections in Pakistan. Afr. J. Biotechnol. 2009, 8, 3921-3926.

23. Rafie, S.; MacDougall, C.; James, C.L. Cethromycin: A promising new ketolide antibiotic for respiratory infections. Pharmacother.: J. Hum. Pharmacol. Drug Ther. 2010, 30, 290-303. [CrossRef] [PubMed]

24. Angeh, J.E.; Huang, X.; Sattler, I.; Swan, G.E.; Dahse, H.; Härtl, A.; Eloff, J.N. Antimicrobial and anti-inflammatory activity of four known and one new triterpenoid from Combretum imberbe (Combretaceae). J. Ethnopharmacol. 2007, 110, 56-60. [CrossRef] [PubMed]

25. Singh, B.; Sahu, P.; Singh, S. Antimicrobial activity of pyrrolizidine alkaloids from Heliotropium subulatum. Fitoterapia 2002, 73, 153-155. [CrossRef]

26. Oluwatoyin, S.M.; Illeogbulam, N.G.; Joseph, A. Phytochemical and antimicrobial studies on the aerial parts of Heliotropium indicum Linn. Ann. Biol. Res. 2011, 2, 129-136.

27. Urzúa, A.; Rezende, M.C.; Mascayano, C.; Vásquez, L. A structure-activity study of antibacterial diterpenoids. Molecules 2008, 13, 882-891. [CrossRef] [PubMed]

28. Jain, S.; Singh, B.; Jain, R. Antimicrobial activity of triterpenoids from Heliotropium ellipticum. Fitoterapia 2001, 72, 666-668. [CrossRef]

29. Torres, R.; Villarroel, L.; Urzua, A.; Delle-Monache, F.; Delle-Monache, G.; Gacs-Baitz, E. Filifolinol, a rearranged geranyl aromatic derivative from the resinous exudate of Heliotropium filifolium. Phytochemistry 1994, 36, 249-250. [CrossRef]

30. Modak, B.; Salina, M.; Rodilla, J.; Torres, R. Study of the chemical composition of the resinous exudate isolated from Heliotropium sclerocarpum and evaluation of the antioxidant properties of the phenolic compounds and the resin. Molecules 2009, 14, 4625-4633. [CrossRef] [PubMed]

31. Urzúa, A.; Echeverría, J.; Rezende, M.C.; Wilkens, M. Antibacterial Properties of 3 H-Spiro [1-benzofuran-2, 1'-cyclohexane] Derivatives from Heliotropium filifolium. Molecules 2008, 13, 2385-2393. [CrossRef] [PubMed]

32. Khattak, S.; Shah, H.U.; Ahmad, W.; Ahmad, M. Biological effects of indigenous medicinal plants Curcuma longa and Alpinia galanga. Fitoterapia 2005, 76, 254-257. [CrossRef] [PubMed]

33. Danziger-Isakov, L.A.; Worley, S.; Arrigain, S.; Aurora, P.; Ballmann, M.; Boyer, D.; Conrad, C.; Eichler, I.; Elidemir, O.; Goldfarb, S. Increased mortality after pulmonary fungal infection within the first year after pediatric lung transplantation. J. Heart Lung Transplant. 2008, 27, 655-661. [CrossRef] [PubMed]

34. Fung, J.J. Fungal infection in liver transplantation. Transpl. Infect. Dis. 2002, 4, 18-23. [CrossRef] [PubMed]

35. Ker, C.C.; Hung, C.C.; Huang, S.Y.; Chen, M.; Hsieh, S.; Lin, C.; Chang, S.; Luh, K. Comparison of bone marrow studies with blood culture for etiological diagnosis of disseminated mycobacterial and fungal infection in patients with acquired immunodeficiency syndrome. J. Microbiol. Immunol. Infect. 2002, 35, 89-93. [PubMed]

36. Al-Sogair, S.; Moawad, M.; Al-Humaidan, Y. Fungal infection as a cause of skin disease in the eastern province of Saudi Arabia: Cutaneous candidosis. Mycoses 1991, 34, 429-431. [CrossRef] [PubMed] 
37. Dismukes, W.E. Introduction to antifungal drugs. Clin. Infect. Dis. 2000, 30, 653-657. [CrossRef] [PubMed]

38. El-Shazly, A.; Abdel-All, M.; Tei, A.; Wink, M. Pyrrolizidine alkaloids from Echium rauwolfii and Echium horridum (Boraginaceae). Z. Naturforschung. C J. Biosci. 1999, 54, 295-300. [CrossRef]

39. Ioset, J.R.; Marston, A.; Gupta, M.P.; Hostettmann, K. Antifungal and larvicidal cordiaquinones from the roots of Cordia curassavica. Phytochemistry 2000, 53, 613-617. [CrossRef]

40. Ioset, J.R.; Marston, A.; Gupta, M.P.; Hostettmann, K. Antifungal and larvicidal meroterpenoid naphthoquinones and a naphthoxirene from the roots of Cordia linnael. Phytochemistry 1998, 47, 729-734. [CrossRef]

41. Singh, B.; Singh, S. Antimicrobial activity of terpenoids from Trichodesma amplexicaule Roth. Phytother. Res. 2003, 17, 814-816. [CrossRef] [PubMed]

42. Ahmad, B.; Ali, N.; Bashir, S.; Choudhary, M.I.; Azam, S.; Khan, I. Parasiticidal, antifungal and antibacterial activities of Onosma griffithii Vatke. Afr. J. Biotechnol. 2009, 8, 5084-5087.

43. Ramakrishnan, G.; Kothai, R.; Jaykar, B.; Rathnakumar, T.V. In vitro Antibacterial Activity of different extracts of Leaves of Coldenia procumbens. Int. J. Pharm. Tech. Res. 2011, 3, 1000-1004.

44. Bahraminejad, S. In vitro and in vivo antifungal activities of Iranian plant species against Pythium aphanidermatum. Ann. Biol. Res. 2012, 3, 2134-2143.

45. Rao, P.R.; Nammi, S.; Raju, A.D.V. Studies on the antimicrobial activity of Heliotropium indicum Linn. J. Nat. Rem. 2002, 2, 195-198.

46. Jain, S.C.; Sharma, R. Antimicrobial activity of pyrrolizidine alkaloids from Heliotropium ellipticum. Chem. Pharm. Bull. 1987, 35, 3487-3489. [CrossRef] [PubMed]

47. Singh, B.; Dubey, M. Estimation of triterpenoids from Heliotropium marifolium Koen. ex Retz. in vivo and in vitro. I. Antimicrobial screening. Phytother. Res. 2001, 15, 231-234. [CrossRef] [PubMed]

48. Das, S.; Das, M.K.; Mazumder, P.M.; Das, S.; Basu, S.P. Cytotoxic activity of methanolic extract of Berberis aristata DC. on colon cancer. Glob. J. Pharmacol. 2009, 3, 137-140.

49. Singh, B.; Sahu, P.; Jain, S.; Singh, S. Antineoplastic and antiviral screening of pyrrolizidine alkaloids from Heliotropium subulatum. Pharm. Biol. 2002, 40, 581-586. [CrossRef]

50. Rahman, M.A.; Mia, M.A.; Shahid, I.Z. Pharmacological and phytochemical screen activities of roots of Heliotropium indicum Linn. Pharmacologyonline 2011, 1, 185-192.

51. Uddin, S.J.; Grice, I.D.; Tiralongo, E. Cytotoxic effects of Bangladeshi medicinal plant extracts. Evid. Based Complement. Altern. Med. 2011, 2011, 1-7. [CrossRef] [PubMed]

52. Ateeq, R.; Mannan, A.; Inayatullah, S.; Akhtar, M.Z.; Qayyum, M.; Mirza, B. Biological evaluation of wild thyme (Thymus serpyllum). Pharm. Biol. 2009, 47, 628-633.

53. Li, Y.; Sun, Z.; Zhuang, X.; Xu, L.; Chen, S.; Li, M. Research progress on microbial herbicides. Crop Prot. 2003, 22, 247-252. [CrossRef]

54. Ghaffari, M.A.; Bano, S.; Hayat, K. Antimicrobial and Phytotoxic Effects of the Plant Heliotropium Dasycarpum L. Int. J. Pharm. Biol. Sci. 2013, 4, 339-345.

55. Saeed, M.; Khan, H.; Khan, M.A.; Simjee, S.U.; Muhammad, N.; Khan, S.A. Phytotoxic, insecticidal and leishmanicidal activities of aerial parts of Polygonatum verticillatum. Afr. J. Biotechnol. 2010, 9, 1241-1244.

56. Mongelli, E.; Desmarchelier, C.; Coussio, J.; Ciccia, G. The potential effects of allelopathic mechanisms on plant species diversity and distribution determined by the wheat rootlet growth inhibition bioassay in South American plants. Rev. Chil. Hist. Nat. 1997, 70, 83-89.

57. Beninger, C.W.; Hall, J.C. Allelopathic activity of luteolin 7-O- $\beta$-glucuronide isolated from Chrysanthemum morifolium L. Biochem. Sys. Ecol. 2005, 33, 103-111. [CrossRef]

58. Machlin, L.J.; Bendich, A. Free radical tissue damage: Protective role of antioxidant nutrients. FASEB J. 1987, 1, 441-445. [PubMed]

59. Stanner, S.A.; Hughes, J.; Kelly, C.N.M.; Buttriss, J. A review of the epidemiological evidence for the 'antioxidant hypothesis'. Public Health Nutr. 2004, 7, 407-422. [CrossRef] [PubMed]

60. Modak, B.; Rojas, M.; Torres, R.; Rodilla, J.; Luebert, F. Antioxidant activity of a new aromatic geranyl derivative of the resinous exudates from Heliotropium glutinosum Phil. Molecules 2007, 12, 1057-1063. [CrossRef] [PubMed] 
61. Modak, B.; Rojas, M.; Torres, R. Chemical analysis of the resinous exudate isolated from Heliotropium taltalense and evaluation of the antioxidant activity of the phenolics components and the resin in homogeneous and heterogeneous systems. Molecules 2009, 14, 1980-1989. [CrossRef] [PubMed]

62. Modak, B.; Torres, R.; Lissi, E.; Monache, F.D. Antioxidant capacity of flavonoids and a new arylphenol of the resinous exudate from Heliotropium sinuatum. Nat. Prod. Res. 2003, 17, 403-407. [CrossRef] [PubMed]

(C) 2016 by the authors; licensee MDPI, Basel, Switzerland. This article is an open access article distributed under the terms and conditions of the Creative Commons Attribution (CC-BY) license (http:/ / creativecommons.org/licenses/by/4.0/). 